\title{
O ACORDO TRIPS E OS PADRÕES INTERNACIONAIS DE PROTEÇÃO DA PROPRIEDADE INTELECTUAL
}

\section{Roberto Luiz Silva ${ }^{1}$}

\section{Resumo:}

O presente artigo tem por finalidade analisar os objetivos imediatos e mediatos subjacentes ao Acordo TRIPS, verificando a adequação e eficiência dos primeiros na consecução dos últimos, indagando, pois, em última análise se o estabelecimento de padrões internacionais mínimos de proteção da propriedade intelectual é o caminho para o fomento e a difusão da inovação tecnológica e para a promoção do balanceamento entre os interesses de produtores e usuários de tecnologia. Para tanto, investigar-se-á o contexto de inclusão da temática da propriedade intelectual na Rodada Uruguai de negociações do GATT, e o modelo de padronização adotado pelo TRIPS.

\section{Palavras-chave:}

Comércio Internacional, Inovação Tecnológica, Organização Mundial do Comércio, Propriedade Intelectual, TRIPS.

\section{THE TRIPS AND THE INTELLECTUAL PROPERTY INTERNATIONAL PATTERNS OF PROTECTION}

\begin{abstract}
:
This article intends to analyze the immediate and near objectives underlying the TRIPS, verifying its adaptation and efficiency, and investigating, in last analysis if the establishment of minimum international protection's patterns of intellectual property is the way for technological innovation's fomentation and diffusion, and for the promotion of counterbalancing between the interests of producers and technology users. For so much, the context of inclusion of the intellectual property subject will be investigated in the GATT's Uruguay Round, and the standardization model adopted by TRIPS.
\end{abstract}

\section{Keywords:}

International Trade, Technological Innovation, World Trade Organization, Intellectual Property, TRIPS.

\footnotetext{
${ }^{1}$ Pós Doutor pela The University of Texas - EUA (2005) e Universität de Barcelona (2016). Doutor em Direito (UFMG). LL.M em EG-Recht (Universität zu Köln - Alemanha). Especialista em Direito Internacional (UNITAR - ONU). Professor Associado na Graduação, Mestrado e Doutorado em Direito da UFMG e no Mestrado Profissional em Inovação Biofarmacêutica do ICB/UFMG. Membro da Sociedade Brasileira de Direito Internacional - SBDI. Coordenador dos Projetos de Extensão: Centro Brasileiro de Estudos sobre a Organização Mundial do Comércio - CEB-OMC/UFMG; e, Grupo de Estudos em Direito Internacional - GEDI/UFMG. Pesquisador do Conselho Nacional de Desenvolvimento Científico e Tecnológico - CNPq. Autor de diversas obras jurídicas.
} 


\section{Introdução}

O Acordo sobre Aspectos Comerciais Relativos aos Direitos de Propriedade Intelectual, ou simplesmente Acordo TRIPS, constitui o Anexo 1-C do Acordo de Marraqueche, instituidor da Organização Mundial do Comércio - OMC, sendo dele parte integrante e, nesta qualidade, figura entre os pilares da estrutura legal básica da referida organização ${ }^{2}$, não estando, portanto, sujeito à adesão em separado, sendo automaticamente vinculativo para o Estado a partir do momento de sua adesão à OMC.

Fruto das deliberações desenvolvidas durante a Rodada do Uruguai de negociações comerciais multilaterais do Acordo Geral sobre Tarifas Aduaneiras e Comércio - GATT, o Acordo TRIPS entrou em vigor em janeiro de 1995 e tem como objetivos imediatos o estabelecimento de princípios básicos e padrões internacionais mínimos - de adoção compulsória pelos Estados-membros -, de proteção da propriedade intelectual.

Dentre os princípios, que em linhas gerais visam coibir o tratamento discriminatório entre os nacionais de cada um dos Estados-membros da OMC, no que diz respeito à proteção da propriedade intelectual, inclui-se o tratamento nacional (art. $3^{\circ}$ ), segundo o qual os Estados- membros devem conferir aos nacionais de outros Estadosmembros tratamento não menos favorável do que aquele conferido aos seus próprios nacionais; e a nação mais favorecida (art. $4^{\circ}$ ), que obriga os Estados-membros a estender, imediata e incondicionalmente, aos nacionais de todos os Estados-membros quaisquer vantagens, favores, privilégios ou imunidades concedidas aos nacionais de um Estadomembro.

Já no que diz respeito aos padrões internacionais mínimos, o Acordo TRIPS fixou diretrizes a serem aplicadas pelos Estados-membros em suas respectivas legislações, estabelecendo, para tanto, sete formas de proteção da propriedade intelectual, quais sejam: direitos autorais e relacionados; marcas; indicação geográfica; desenho industrial;

\footnotetext{
${ }^{2}$ O Sistema OMC estrutura-se sobre 6 acordos principais: Acordo de Marraqueche (estabelece a OMC); Acordo Multilateral sobre Comércio de Bens; Acordo Multilateral sobre Comércio de Serviços (GATS); Acordo sobre Aspectos Comerciais Relativos aos Direitos de Propriedade Intelectual (TRIPS); Acordo sobre Resolução de Controvérsias; e, Mecanismo de Revisão de Políticas Comerciais.
} 
patentes; topografias de circuitos integrados; e, segredo industrial. A observância dos princípios e a implementação dos padrões pelos Estados - membros conduziria o Acordo TRIPS ao alcance de seus objetivos mediatos declarados em seu art. $7^{\circ}$, quais sejam: a promoção da inovação tecnológica; a transferência e disseminação da tecnologia; a geração de vantagens mútuas para produtores e usuários do conhecimento tecnológico, de forma a promover o bem-estar social e econômico e equilibrar direitos e obrigações.

Não obstante, muito se tem discutido quanto à eficiência do Acordo TRIPS na consecução de seus objetivos mediatos, o que se pode atribuir à insatisfação frequentemente externada pelos Estados-parte em desenvolvimento, que reivindicam que a interpretação conferida ao referido acordo pelos Estados-membros desenvolvidos e as demandas pelo estabelecimento de um TRIPS-plus adicional - aumentando o grau de proteção da propriedade intelectual - ignoram suas necessidades locais, interesses nacionais, capacidade tecnológica e institucional e condições de saúde pública.

De fato, ao longo dos quase um quarto de século de vigência do Acordo TRIPS, a concretização dos positivos efeitos prometidos e enunciados quando de sua negociação foi, no mínimo, tímida, não se podendo dizer que tenha efetivamente colaborado para a promoção da transferência de tecnologia dos Estados-membros desenvolvidos para os em desenvolvimento, por exemplo. Esta constatação nos conduz ao seguinte questionamento: seria a ineficácia do Acordo TRIPS na consecução de seus objetivos mediatos demonstração da inviabilidade do estabelecimento de padrões internacionais de proteção da propriedade intelectual? Ou seria apenas a demonstração da falibilidade do modelo de padronização adotado?

Para responder a esta questão, pretendemos desenvolver nosso trabalho em quatro aspectos. Primeiramente elaborar uma breve contextualização da proteção da propriedade intelectual no cenário internacional até o advento do Acordo TRIPS para, posteriormente, enunciar o paradoxo entre os objetivos preconizados em 1994 e a realidade evidenciada neste período de sua aplicação, concluindo ao final que o Acordo TRIPS, que prevê um tamanho único de proteção à propriedade intelectual - one-size-fitsall - que, supostamente, serviria ao interesse de todos, em verdade vem beneficiando tão somente os interesses dos Estados- membros da OMC desenvolvidos - com ressalva para 
a China -, e mais especificamente das empresas transnacionais.

\section{Breve Contextualização da Proteção da Propriedade Intelectual}

A propriedade intelectual, segundo a Organização Mundial de Propriedade Intelectual - OMPI, é um instituto jurídico que se refere a gama de direitos atribuídos pela lei aos produtos da atividade intelectual nos ramos industrial, científico, literário e artístico, como forma de salvaguardar os criadores e produtores de bens e serviços intelectuais através da outorga do direito de controlar, por determinado período de tempo, a confecção de seus produtos, conferindo-lhes, assim, expressão moral e econômica, e, por conseguinte, promovendo a criatividade e encorajando o comércio justo em prol do desenvolvimento econômico e social ${ }^{3}$.

Não obstante remontarem as origens arcaicas da propriedade intelectual para a Roma antiga - ao menos do ponto de vista dos países de tradição jurídica romanogermânica -, quando já se tinha um esboço do que viriam a ser os direitos autorais, a proteção dos frutos do intelecto humano, seja sob a forma de manifestações linguísticas ou inventos, só começou a ganhar os contornos que atualmente a identificam a partir da Idade Média, quando os monarcas, com o intuito político-religioso de controlar as informações que circulavam em seus reinos, passaram a outorgar a determinadas corporações de ofício - associações de artesãos - o direito de regular um setor produtivo específico.

A questão, contudo, só ganhou notoriedade internacional com o advento da Revolução Industrial desencadeadora da intensificação do desenvolvimento de tecnologias, do fluxo de mercadorias e da progressiva internacionalização do mercado, fatores que apontavam para a necessidade de harmonização das legislações nacionais como meio de superar problemas práticos advindos de sua diversidade e dotar de maior efetividade a proteção conferida à propriedade intelectual.

A insegurança gerada pela ausência de um tratado internacional que versasse

\footnotetext{
3 The Concept of Intellectual Property. WIPO Intellectual Property Handbook: Policy, Law and Use. Disponível em: <http://www.wipo.int/export/ sites/www/about -ip/en/iprm/pdf/ch1.pdf >. Acesso em $22 \mathrm{de}$ março de 2018 .
} 
sobre propriedade intelectual ficou clara quando, em 1873, o governo do Império austro húngaro convidou inventores de diversas nacionalidades para expor seus trabalhos em uma feira científica organizada em Viena e, como resposta, recebeu manifestações de apreensão e desconfiança motivadas pela inadequação da proteção legal oferecida aos inventos exibidos.

Como forma de incentivar a participação na mencionada feira científica, o governo austro-húngaro promulgou um decreto de vigência transitória com a finalidade de proteger as invenções produzidas por expositores estrangeiros. Esta medida, contudo, era meramente paliativa e serviu apenas para impulsionar ainda mais os debates que se instalavam sobre a temática, fomentando a organização de congressos por toda a Europa, os quais invariavelmente culminavam na elaboração de cartilhas elencando os princípios que deveriam nortear a construção de um sistema efetivo de proteção da propriedade intelectual e na conclamação dos governantes para a construção de um entendimento internacional acerca da proteção patentária.

O mais importante deles foi o Congresso Internacional de Propriedade Industrial realizado em Paris em 1878, durante o qual foi planejada uma Conferência Diplomática Internacional para a qual seriam convidados representantes de diversos países com o fim de determinar as bases para o estabelecimento de uma legislação uniforme de proteção da propriedade intelectual.

Referida Conferência, convocada para o ano de 1880, resultou na elaboração de uma proposta de união internacional para a proteção da propriedade intelectual, que foi finalmente aprovada e originalmente assinada por 11 Estados $^{4}$ durante a Conferência Diplomática subsequente igualmente realizada em Paris, no ano de 1883, e que, portanto, recebeu o nome de Convenção de Paris para a Proteção da Propriedade Industrial.

Por meio do tratado em comento, em linhas gerais, comprometeram-se as partes contratantes a: (i) conferir ao inventor estrangeiro, desde que domiciliado em país signatário do tratado, proteção igual àquela dispensada ao inventor nacional; (ii) conceder prioridade de tramitação ao pedido de patente que já estivesse depositado perante os

\footnotetext{
${ }^{4}$ Bélgica, Brasil, El Salvador, Espanha, França, Guatemala, Holanda, Itália, Portugal, Sérvia e Suíça. Assim que a Convenção entrou em vigor, um ano mais tarde (julho/1884), Equador, Tunísia e Reino Unido aderiram.
} 
órgãos competentes de um dos países signatários, de modo que todos os demais pedidos considerar-se-iam como depositados no mesmo dia em que feito o primeiro depósito , desde que formulados em até 12 (doze) meses a contar do último; (iii) considerar os pedidos de patente de forma independente, de forma que a concessão de patente em um dos países signatários do tratado não obriga os de mais a conceder a patente, até mesmo porque cada país signatário tem sua própria legislação.

Posteriormente à Convenção de Paris, ainda como resultado do esforço internacional de implementação de um sistema eficaz de proteção da propriedade intelectual, f oi elaborada, em 1886, a Convenção de Berna para a Proteção de Trabalhos Artísticos e Literários, que igualmente redundou na formação de uma união internacional, por meio da qual, basicamente, comprometeram -se as partes signatárias a: (i) conferir ao autor nacional e ao estrangeiro a mesma proteção, sem qualquer diferenciação; (ii) conceder a proteção ao autor independentemente de qualquer formalidade ou registro, ou seja, automaticamente; e (iii) garantir o gozo e a fruição dos direitos autorais independentemente da existência de concessão de proteção ao trabalho no país de origem.

Cada uma dessas Convenções ensejou a formação de um escritório administrativo, os quais, todavia, se uniram em 1893, originando o Escritório Internacional para a Proteção da Propriedade Intelectual - BIRPI que se localizava em Genebra e era supervisionado pelo governo suíço.

No entanto, durante a Conferência de Estocolmo realizada em 1967 com o fim de revisar os termos das Convenções de Paris e de Berna, seguindo a onda instalada no cenário internacional no contexto pós Segunda Guerra, os membros signatários decidiram transformar o BIRPI em uma organização internacional cuja coordenação passou a ser compartilhada por todos e não mais supervisionada pela Suíça, a qual se convencionou chamar Organização Mundial da Propriedade Intelectual - a OMPI.

Esta alteração estrutural, contudo, apesar de seguida pela transformação da OMPI em agência da ONU, por meio de Acordo assinado em 1974, não foi suficiente para conter a insatisfação dos países desenvolvidos com o sistema internacional de proteção da propriedade intelectual em vigor, assentado precipuamente sobre as Convenções de Paris e de Berna que, não obstante terem explícito intuito harmonizador, dotavam os Estados 
signatários de ampla liberdade legislativa, exigindo-lhes apenas paridade de tratamento entre nacionais e estrangeiros. Essa característica, aliada à progressiva globalização do comércio internacional e à ausência de um mecanismo próprio de solução de controvérsias ${ }^{5}$ era interpretada pelos países desenvolvidos como evidência da precariedade e incipiência do sistema.

Deve-se ter em mente que apesar da relativa ampliação de suas atividades ao longo de sua existência, sobretudo a partir da assinatura do Tratado de Cooperação em matéria Patentária (PCT), concluído em Washington em1970, quando se tornou responsável pelo registro de pedidos internacionais de depósito de patentes, a OMPI sempre teve suas atribuições marcadas pelo caráter precipuamente administrativo, de gerenciamento dos tratados internacionais em matéria de propriedade intelectual, o que gerava por parte dos países desenvolvidos constantes questionamentos acerca da efetividade da pretendida proteção da propriedade intelectual que intentava promover.

A situação se agravou durante a década de 1980, quando diversas empresas estabelecidas em países em desenvolvimento lançaram mão de artifícios como a imitação e a pirataria na tentativa de fazer o catching-up tecnológico e aumentar sua parcela de participação no mercado internacional. Em resposta, as grandes empresas produtoras de inovação tecnológica, principalmente dos setores de software, microeletrônicos, entretenimento, indústria química e farmacêutica e biotecnologia, oriundas de países desenvolvidos, notadamente dos Estados Unidos, percebendo a propriedade intelectual como um patrimônio estratégico e notando as perdas de oportunidades comerciais no exterior, iniciaram um processo de lobby, pressionando seus respectivos governos para que buscassem, no cenário internacional, estabelecer níveis adequados de proteção para seus inventos.

O governo dos Estados Unidos, já desgostoso dos progressos feitos pela OMPI na proteção da propriedade intelectual, e reconhecendo que o seu crescimento econômico e geração de vantagem comparativa atrelar-se-ia cada vez mais profundamente ao comércio global de informações e conhecimento, iniciou, com o apoio dos países integrantes da então Comunidade Econômica Européia - CEE, forte campanha para

\footnotetext{
${ }^{5}$ Uma vez que era da competência da Corte Internacional de Justiça - CIJ dirimir eventuais disputas concernentes à aplicação das referidas Convenções.
} 
inclusão da temática no fórum de negociações comerciais multilaterais do GATT. Não obstante o fracasso inicial da tentativa de adoção de um Código Anti- Contrafação no seio do GATT, o que foi idealizado - porém não aprovado - na Rodada Tóquio, durante a Conferência Ministerial de Punta del Este, realizada em 1986, os Estados Unidos e a CEE lograram inserir entre as questões a serem tratadas no mandato da Rodada subsequente de negociações - Rodada Uruguai -, a discussão acerca dos aspectos comerciais relativos aos direitos de propriedade intelectual, apesar da relutância dos países em desenvolvimento, capitaneados por Brasil e Índia, que reputavam que o fórum adequado para tanto seria a OMPI e não o GATT.

Estes, seja por terem equivocadamente acreditado que os direitos de propriedade intelectual representariam apenas mais um dentre os vários temas inseridos no mandato da Rodada do Uruguai, permanecendo céticos quanto à sua sobrevivência até o final das negociações, seja por terem vislumbrado a temática como moeda de troca para inserção de outras questões que lhes eram interessantes, como a discussão acerca de produtos têxteis e agrícolas, ou ainda, por temerem retaliações comerciais, terminaram por atuar de forma conivente com a adesão do tópico àquela agenda de negociações, acabando por vela inserida no mandato da Rodada do Uruguai.

Uma vez inserida a temática dos direitos de propriedade intelectual no mandato da Rodada do Uruguai (1986-1994), rapidamente cuidaram os países desenvolvidos, sob os auspícios de Estados Unidos, CEE, Japão, Suíça e Austrália, de elaborar, já nos primeiros meses de 1990, o esboço do que viria a ser o Acordo TRIPS, em evidente contraste ao que era estabelecido pela Convenção de Paris de 1883. Isso porque, ao invés de três princípios básicos, a proposta previa regras-padrão mínimas que estabeleciam uma série ampla de conceitos e exigências a serem incluídos nas legislações dos Estadosmembros, em uma espécie de lei-tipo; em contraposição à marcante flexibilidade, introduzia determinações rígidas acerca da forma como as leis nacionais dos Estadosmembros referentes à propriedade intelectual deveriam ser aplicadas no âmbito administrativo e judicial; por fim, instituía um sistema internacional de solução de controvérsias, de modo a evitar que os dissídios afetos à temática ficassem sem solução mandatória. 
Como já era de se esperar, esta proposta foi recebida com irresignação pelos países em desenvolvimento, visto que representava o recrudescimento do sistema até então vigente de proteção da propriedade intelectual, contra o qual já se voltavam, pretendendo uma maior flexibilização, desde a década de 1970 quando lograram rever internacionalmente alguns pontos da Convenção de Paris. E, então, como resposta ao que reputavam ser uma afronta à sua soberania, os países em desenvolvimento se uniram e elaboraram uma contraproposta de regulamentação internacional da propriedade intelectual muito mais limitada em escopo e com poucos aspectos normativos.

Por óbvio, em virtude de sua industrialização tardia, o que refletia em sua incipiente capacidade tecnológica, os países em desenvolvimento não tinham qualquer intenção de fortalecer a proteção da propriedade intelectual, visto que esta mudança não proporcionaria vantagens competitivas para as suas empresas no mercado internacional. Do ponto de vista dos países em desenvolvimento, portanto, os benefícios supostamente advindos de tal proteção, como o incremento do progresso tecnológico mundial, eram suplantados pelas desvantagens de não mais poder adaptar a tecnologia estrangeira, ou importar produtos vindos de fontes alternativas ou mais acessíveis.

O indissolúvel conflito entre os interesses de países desenvolvidos e em desenvolvimento no que diz respeito à temática da propriedade intelectual instalou um impasse de difícil transposição nas negociações da Rodada do Uruguai, que se encontrava entravada pela ausência de consenso também em outros tópicos da agenda. Contudo, foi exatamente o antagonismo entre os propósitos de países desenvolvidos e em desenvolvimento que viabilizou um desfecho exitoso para esta a Rodada, porque permitiu que as negociações progredissem através de concessões mútuas. Tivessem os pontos da agenda sido negociados isoladamente, muito provavelmente não se teria logrado alcançar um acordo.

E foi devido a esta dinâmica de negociações, que proporcionava aos países em desenvolvimento a possibilidade de auferir ganhos comerciais e melhorar o acesso ao mercado internacional em setores como agricultura, têxteis, produtos tropicais e salvaguardas - aliada ao temor da adoção de medidas unilaterais retaliatórias por parte dos países desenvolvidos caso a proteção da propriedade intelectual não fosse incorporada ao 
sistema do GATT e ainda à percepção de que os benefícios advindos da resolução multilateral das diferenças acerca da temática seria muito mais vantajosa do que por meio de tratativas bilaterais -, que o Acordo TRIPS foi aprovado. E, assim como os demais acordos resultantes das deliberações encetadas ao longo da Rodada Uruguai, dentre os quais destaque-se o Acordo estabelecendo a $\mathrm{OMC}$, integra o compromisso único - single undertaking - firmado pelos Estados signatários do Ato Final da Rodada, em Marraqueche aos 15 de abril de 1994, de modo que a adesão à OMC implicaria a aceitação de todos os resultados da Rodada Uruguai, sem exceção.

A versão final do Acordo TRIPS, que em seu teor (art. 72) veda a possibilidade de aceitação do texto com ressalvas - já prevendo as distorções e a perda de efetividade que destas ressalvas poderiam resultar -, espelhava a proposta editada pelos países desenvolvidos, contendo, pois, normas-padrão mínimas de proteção da propriedade intelectual a serem incorporadas na legislação nacional dos Estados-membros; estipulações acerca da forma como tal proteção deveria ser internalizada nos âmbitos administrativo e judicial; além da previsão de um mecanismo próprio de solução de controvérsias. As considerações dos países em desenvolvimento, por sua vez, foram refletidas apenas em dois dispositivos, quais sejam os artigos $7^{\circ}$ e $8^{\circ}, 19$ responsáveis, respectivamente, por delinear os objetivos e princípios norteadores do Acordo TRIPS.

\section{O Paradoxo entre os Objetivos e a Realidade Evidenciada pelo Acordo TRIPS}

Desde que entrou em vigor, em $1^{\circ}$ de janeiro de 1995, o Acordo TRIPS tem sido fonte de inúmeras controvérsias. Alguns se insurgem contra o modelo de padronização adotado pelo indigitado instrumento internacional, arguindo ser o mesmo ineficiente para promover os objetivos em seu bojo declarados; outros apontam que a proteção da propriedade intelectual empreendida pelo Acordo TRIPS seria contrária ao propósito de liberalização do comércio intrínseco à OMC; e há ainda aqueles que, partindo para um debate mais aprofundado, contestam a própria legitimidade da proteção da propriedade intelectual.

Não obstante o interesse de que se cercam tais discussões, o presente estudo 
ficará circunscrito à análise das questões envolvendo a ineficiência do modelo de padronização adotado pelo Acordo TRIPS na consecução dos objetivos que elenca, sendo os demais pontos controvertidos analisados apenas de forma secundária e tangencial, nos estritos limites de sua interseção com a questão central deste artigo.

Pois bem, os críticos do modelo de uniformização das legislações nacionais promovido pelo Acordo TRIPS advogam que a abordagem one-size-fits-all, que impõe a todos os Estados-membros, independentemente de seu grau de desenvolvimento, os mesmos patamares mínimos e compulsórios de proteção da propriedade intelectual, não seria adequada para promover os objetivos subjacentes à criação do Acordo TRIPS, enunciados em seu texto por meio do supramencionado art. $7^{\circ}$, quais sejam: promover a inovação tecnológica, a transferência e difusão da tecnologia; contribuir para as vantagens mútuas entre produtores e usuários de tecnologia, de modo conducente ao bem-estar social e econômico e ao equilíbrio entre direitos e obrigações. Em última análise, o acordo em comento encerraria uma contradição interna, visto que o modo como operacionalizado não seria idôneo a alcançar a finalidade última em seu bojo declarada.

Isto porque o impacto da proteção da propriedade intelectual no fomento dos objetivos supra declinados, mormente no desenvolvimento econômico e social, seria sensível ao contexto, estando, pois, sujeito a variações de acordo com o setor industrial e, principalmente, conforme o país analisado:

(...) há um crescente consenso no sentido de que o impacto da proteção da propriedade intelectual seja significativamente sensível ao contexto. Há boas razões para concluir, por exemplo, que o papel da patente no processo de desenvolvimento do setor automotivo é bastante diverso do papel da patente no desenvolvimento do setor farmacêutico. Similarmente, há boas razões para concluir que o papel da proteção da propriedade intelectual seja diferente entre as economias dos países industrializados, em desenvolvimento e menos desenvolvidos, e que até mesmo entre estas amplas categorias de desenvolvimento econômico haja variações dependendo de inúmeros fatores, como tamanho do mercado, capacidade local para inovação e assim por diante ${ }^{6}$.

${ }^{6}$ ABBOTT, Frederick M. The enduring enigma of TRIPS: a challenge for the world economic system. Journal of International Economic Law, vol. 1, art 4, p. 497- 521, Oxford University Press. Disponível em <http://papers.ssrn.com/sol3/papers.cfm?abstract_id=915040 >. Acesso em 15 de março de 2018. 
Por óbvio, em vista das especificidades de cada país - políticas, mercadológicas, sociais, econômicas -, constatação diversa não se poderia esperar, e o equívoco do Acordo TRIPS parece residir exatamente em não ter dado a devida e merecida atenção a estas peculiaridades. É que, quando da celebração do referido acordo, os Estados contratantes encontravam-se em diferentes estágios de desenvolvimento, havendo entre alguns deles um considerável - e a curto-prazo intransponível - hiato. Não obstante, este fator foi considerado tão somente para fins de fixação do termo inicial de vigência do acordo, tendo sido concedido aos Estados-membros em desenvolvimento e menos desenvolvido a possibilidade de postergação da data inicialmente avençada, nos termos dos arts. 65 e 66 do Acordo TRIPS ao dispor que:

Artigo 65 - Disposições Transitórias

Sem prejuízo do disposto nos parágrafos 2, 3 e 4, nenhum Membro estará obrigado a aplicar as disposições do presente Acordo antes de transcorrido um prazo geral de um ano após a data de entrada em vigor do Acordo Constitutivo da OMC.

1. Um País Membro em desenvolvimento tem direito a postergar a data de aplicação das disposições do presente Acordo, estabelecida no parágrafo 1, por um prazo de quatro anos, com exceção dos Artigos 3, 4 e 5.

(..)

4. Na medida em que um país Membro em desenvolvimento esteja obrigado pelo presente Acordo a estender a proteção patentária de produtos a setores tecnológicos que não protegia em seu território na data geral de aplicação do presente Acordo, conforme estabelecido no parágrafo 2, ele poderá adiar a aplicação das disposições sobre patentes de produtos da Seção 5 da Parte II para tai s setores tecnológicos por um prazo adicional de cinco anos.

5. Um Membro que se utiliza do prazo de transição previsto nos parágrafos $1,2,3$ e 4 assegurará que quaisquer modificações nas suas legislações, regulamentos e prática feitas durante esse praz o não resultem em um menor grau de consistência com as disposições do presente Acordo.

Artigo 66 - Estados-membros menos desenvolvidos

1. Em virtude de suas necessidades e requisitos especiais, de suas limitações econômicas, financeiras e administrativas e de sua necessidade de flexibilidade para estabelecer uma base tecnológica viável, os países de menor desenvolvimento relativo Membros não estarão obrigados a aplicar as disposições do presente Acordo, com exceção dos Artigos 3, 4 e 5, durante um prazo de dez anos contados a partir da data de aplicação estabelecida no parágrafo 1 do Artigo 65. O Conselho para TRIPS, quando receber um pedido devidamente fundamentado de um país de menor 
desenvolvimento relativo Membro, concederá prorrogações desse prazo. (...)

Há que se ter em mente que a proteção da propriedade intelectual é uma mera ferramenta legal idealizada para funcionar como mola propulsora de um processo de causa e efeito que parte da diminuição dos riscos intrínsecos à atividade de pesquisa, passa pela atração de investimentos para o setor de Pesquisa e Desenvolvimento - P\&D, pelo estímulo e incremento da atividade inovativa e criativa, pela disseminação da tecnologia, colaborando, ao longo deste percurso, para a promoção do desenvolvimento econômico e social. Todavia, nenhum desses benéficos efeitos poderia ser sentido na ausência da causa original, pressuposto da efetividade da proteção da propriedade intelectual, qual seja, a existência de um sistema nacional de inovação organizado, com objetivos e estratégias definidas.

Seria demasiadamente ilusório acreditar que a proteção da propriedade intelectual isoladamente considerada fosse capaz de provocar o completo desenrolar de todo o processo supra descrito, sendo presumível que há uma gama de outros fatores determinantes que podem obstar que seu fim último seja atingido. $\mathrm{O}$ primeiro e mais fundamental deles é, certamente, a existência de um sistema nacional de inovação.

Ocorre que, a própria experiência dos países desenvolvidos demonstra que não se constrói um sistema nacional de inovação operante e eficiente da noite para o dia, ou sequer em uma década, mormente quando se trata de países em grau incipiente ou intermediário de industrialização. Isto porque um sistema nacional de inovação é formado pela coordenação orquestrada de diversos atores - tais como empresas, universidades e institutos de pesquisa - além de setores da economia, pressupondo políticas públicas orientadas para o avanço tecnológico e para o fomento do comércio internacional, e demandando investimentos internos, mormente na área de educação, a fim de injetar no mercado pessoal qualificado e capacitado:

Uma importante característica que distingue países que apoiam empresas competitivas e inovadores reside nos sistemas de educação e treinamento que fornecem a estas firmas um fluxo de pessoas com conhecimento e habilidades. (...) Os exemplos de Coréia e de Taiwan, e de outros 'tigres' asiáticos, podem ser vistos como casos notavelmente bem - sucedidos de crescimento orientado pela educação. Assim, de acordo com os autores de seus estudos, a capacidade das empresas desses países em evoluir rapidamente dos produtos relativamente simples que fabricavam nos anos 1950 e 1960 para outros mais complexos e tecnologicamente sofisticados que passaram a produzir com sucesso nos anos 
1980, tornou- se possível graças à disponibilidade local de uma força de trabalho jovem dotada da escolaridade necessária para esses novos empregos. Por seu lado, os casos da Argentina e Israel sugerem, no entanto, que a disponibilidade de uma força de trabalho educada não é suficiente em si. (...)

Outro fator que parece diferenciar os países cujas empresas são efetivamente inovadoras daqueles que não as possuem está no pacote de políticas fiscais, monetárias e de comércio internacional. Nos casos em que as exportações se tornaram atraentes para as empresas, estas foram induzidas a inovar e competir. Nos casos em que as exportações têm sido difíceis ou insuficientemente atrativas, as empresas tenderam a satisfazer-se com seus mercados locais e a pedir proteção quando estavam em perigo. (...) O que se quer dizer com isso é que os incentivos à exportação são importantes porque para a maioria dos países, se as empresas não competem no mercado mundial, elas nunca chegam a competir fortemente ${ }^{7}$.

Não há dúvidas, contudo, de que para que os primeiros resultados sejam sentidos é necessário não só que as políticas se desenvolvam de forma continuada, como igualmente que transcorra um significativo lapso temporal.

Entretanto, quando da entrada em vigor do Acordo TRIPS, apenas os Estadosmembros desenvolvidos - ressalva feita para a Coréia do Sul - possuíam um sistema nacional de inovação estruturado e um setor de P\&D em condições de gerar densidade considerável de conhecimento e tecnologia. O resultado é que a incorporação dos patamares mínimos internacionais de proteção da propriedade intelectual pelos Estadosmembros em desenvolvimento não trouxe o estímulo e os benefícios locais idealizados por estes e propagandeados pelos Estados-membros desenvolvidos quando da negociação do Acordo TRIPS.

Estes benefícios, em verdade - e nada surpreendentemente -, foram quase que exclusivamente sentidos pelos próprios Estados-membros desenvolvidos, ressalva novamente feita para a Coréia do Sul e também, mais recentemente, para a China, cuja regra é exatamente que seja a exceção. Tanto é assim que, após quase 25 anos de vigência do Acordo TRIPS, ainda é irrisória a produção tecnológica dos Estados-membros em desenvolvimento frente à pujança dos desenvolvidos.

Por óbvio, pouco ou nenhum efeito concreto poderia advir de uma legislação nacional que minimiza os riscos inerentes à atividade de pesquisa a partir do aumento da apropriação do conhecimento empregado e da tecnologia desenvolvida, quando se está

\footnotetext{
${ }^{7}$ NELSON, Richard R. As fontes do crescimento econômico. Tradução: Adriana Gomes de Freitas. São
} Paulo: Ed. Unicamp, 2006, p. 446. 
diante de um país com um sistema de inovação precário e insipiente - muitas vezes até mesmo inexistente -. É assim que, dos 144 Estados signatários do PCT, 14 representam mais de $90 \%$ do total dos pedidos de depósito internacional de patentes, enquanto que os 130 restantes, dentre os quais a maioria esmagadora constituída de países em desenvolvimento, excluídos China e Coréia do Sul, representam um volume de apenas $7,9 \%$ deste total.

O que se verifica, portanto, é que longe de atuar como mecanismo de promoção do desenvolvimento econômico e inovativo dos diversos Estados-membros da OMC, em consonância com o interesse público subjacente à proteção da propriedade intelectual e na esteira do objetivo último em seu bojo enunciado, o Acordo TRIPS, em verdade, vem servindo de meio de perpetuação do hiato tecnológico existente entre Estados-membros desenvolvidos e em desenvolvimento, inviabilizando a concretização do catching-up. Isto porque, desde o princípio, o referido Acordo vem sendo manipulado de modo convergente aos interesses de um seleto grupo de empresas que lograram alcançar posição de influência no cenário político e econômico internacional (NELSON, 2006), e que, coincidentemente ou não, correspondem à quase integralidade dos 50 maiores depositários de patentes através do sistema PCT, conforme Tabela originária de dados extraídos da $\mathrm{OMPI}^{87}$, apresentada abaixo.

\footnotetext{
${ }^{8}$ Disponível em <http://www.wipo.int/pressroom/en/articles/2011/article_0004.html >. Acesso em 06 de março de 2018.
} 


\section{Tabela 1}

\section{Ranking dos 50 maiores depositários de patentes através do Sistema PCT}

\begin{tabular}{|c|c|c|c|}
\hline Posição & Empresa & $\begin{array}{l}\text { País de } \\
\text { Origem }\end{array}$ & $\begin{array}{l}\text { № de } \\
\text { Pedidos }\end{array}$ \\
\hline 10 & Panasonic & Japão & 2.154 \\
\hline $2^{0}$ & ZTE & China & 1.863 \\
\hline $3^{0}$ & Qualcomm & EUA & 1.677 \\
\hline $4^{0}$ & Huawei & China & 1.528 \\
\hline $5^{0}$ & Philips & Holanda & 1.435 \\
\hline $6^{0}$ & Bosch & Alemanha & 1.301 \\
\hline $7^{0}$ & LG & Coréia & 1.298 \\
\hline $8^{\circ}$ & Sharp & Japão & 1.286 \\
\hline 90 & Ericsson & Suécia & 1.149 \\
\hline $10^{\circ}$ & NEC & Japão & 1.106 \\
\hline $11^{\circ}$ & Toyota & Japão & 1.095 \\
\hline $12^{\circ}$ & Siemens & Alemanha & 833 \\
\hline $13^{\circ}$ & Basf & Alemanha & 818 \\
\hline $14^{\circ}$ & Mitsubishi Elet. & Japão & 726 \\
\hline $15^{\circ}$ & Nokia & Finlândia & 632 \\
\hline $16^{\circ}$ & $3 \mathrm{M}$ & EUA & 586 \\
\hline $17^{0}$ & Samsung & Coréia & 578 \\
\hline $18^{\circ}$ & $\mathrm{HP}$ & EUA & 564 \\
\hline $19^{\circ}$ & Fuji & Japão & 476 \\
\hline $20^{\circ}$ & Microsoft & EUA & 469 \\
\hline $21^{\circ}$ & Dupont & EUA & 452 \\
\hline $22^{\circ}$ & IBM & EUA & 416 \\
\hline $23^{0}$ & Mitsubishi Ind. & Japão & 391 \\
\hline $24^{\circ}$ & Canon & Japão & 379 \\
\hline $25^{\circ}$ & Hitachi & Japão & 373 \\
\hline $26^{\circ}$ & Bosch & Alemanha & 371 \\
\hline
\end{tabular}

\begin{tabular}{|c|c|c|r|}
\hline Posição & Empresa & $\begin{array}{c}\text { País de } \\
\text { origem }\end{array}$ & $\begin{array}{l}\text { № de } \\
\text { pedidos }\end{array}$ \\
\hline $27^{\circ}$ & Procter Gamble & EUA & 359 \\
\hline $28^{\circ}$ & Sony & Japão & 347 \\
\hline $29^{\circ}$ & Nokia/Siemens & Finlândia & 345 \\
\hline $30^{\circ}$ & NXP & Holanda & 320 \\
\hline $30^{\circ}$ & Sumitomo & Japão & 320 \\
\hline $32^{\circ}$ & Toshiba & Japão & 313 \\
\hline $33^{\circ}$ & Applied & EUA & 313 \\
\hline $34^{\circ}$ & Materials & & \\
\hline $35^{\circ}$ & Homson & França & 311 \\
\hline $36^{\circ}$ & Comissariado & Japão & 309 \\
\hline $37^{\circ}$ & França & 308 \\
\hline $38^{\circ}$ & U. Califórnia & EUA & 306 \\
\hline $38^{\circ}$ & Murata & Japão & 306 \\
\hline $40^{\circ}$ & Fraunhofer & Alemanha & 298 \\
\hline $40^{\circ}$ & NTT & Japão & 298 \\
\hline $42^{\circ}$ & Motorola & EUA & 290 \\
\hline $42^{\circ}$ & Pioneer & Japão & 290 \\
\hline $44^{\circ}$ & Sony Ericsson & Suécia & 289 \\
\hline $44^{\circ}$ & Dow Global & EUA & 289 \\
\hline $44^{\circ}$ & Medtronic & EUA & 289 \\
\hline $47^{\circ}$ & Kodak & EUA & 284 \\
\hline $48^{\circ}$ & Kyocera & Japão & 279 \\
\hline $49^{\circ}$ & Alcatel & França & 275 \\
\hline $49^{\circ}$ & Fujifilm & Japão & 275 \\
\hline $49^{\circ}$ & Henkel & Alemanha & 275 \\
\hline
\end{tabular}

É interessante notar que a maioria das empresas transnacionais elencadas no ranking da OMPI são oriundas de países desenvolvidos, sendo que para galgar a posição ora observada, muitas delas se valeram de subterfúgios não ortodoxos contra os quais hoje se voltam, empenhando-se em taxá-los de ilícitos com fincas a impedir que suas concorrentes a eles recorram e que se tornem competitivas.

Com efeito, não foram poucos - para não dizer todos - os países desenvolvidos que lançaram mão de mecanismos como a proteção tarifária, a cooptação de mão de obra estrangeira especializada, e incentivaram ardis como a engenharia reversa, a espionagem industrial, a violação patentária e o contrabando de maquinário, para promover o avanço tecnológico quando se encontravam em processo de catching-up. Porém, agora que lograram superar esta fase, se valem de sua representatividade e de seu poderio internacional, para implementar um sistema que veda tais práticas, garantindo que sua 
posição de supremacia se consolide (CHANG, 2004).

Vale salientar, por fim, não ser intenção deste artigo colocar em xeque o instituto da propriedade intelectual, ou muito menos incentivar a anarquia internacional no que diz respeito a questão assaz relevante. Assim como é certo que o comércio internacional deve dar- se segundo regras mínimas que garantam os interesses das partes envolvidas - para o que vem colaborar a proteção da propriedade intelectual -, é igualmente certo que a garantia dos interesses das partes envolvidas não pode dar-se de modo tal que implique a anulação do interesse público subjacente ao comércio internacional. Em outras palavras, e trazendo a consideração para o campo específico do presente trabalho, a proteção da propriedade intelectual não pode nortear-se exclusivamente pelos interesses de particulares, devendo, de outro modo, orientar-se sempre em estrita consonância com o interesse público que lhe é peculiar, promovendo, na medida do possível, o balanceamento entre eles.

\section{Conclusão}

A abordagem one-size-fits-all adotada pelo Acordo TRIPS, que prevê um tamanho único de proteção à propriedade intelectual que supostamente serviria ao interesse de todos, em verdade vem beneficiando tão somente os interesses dos Estadosmembros desenvolvidos com ressalva para a China -, e mais especificamente das empresas transnacionais.

Com efeito, os objetivos declarados no bojo do Acordo TRIPS, no sentido de que a propriedade intelectual fosse protegida e aplicada de forma a contribuir para a inovação e disseminação da inovação tecnológica e para a promoção do bem estar social e econômico, serviram apenas de ferramenta hipócrita de negociação, tendo sido absolutamente negligenciados ao longo dos quase 25 anos de vigência do Acordo.

Por certo, o estímulo ceticamente idealizado pelos Estados-membros em desenvolvimento, quando da negociação do Acordo TRIPS, seria sentido localmente, isto é, a incorporação, nas legislações internas, auxiliaria no incremento da atividade inovativa nacional, atraindo mais pesquisadores e fomentando o setor de $\mathrm{P} \& \mathrm{D}$ interno, a partir da diminuição dos riscos e do aumento da apropriação do conhecimento empregado e da tecnologia desenvolvida. Entretanto, sua apreensão em relação ao referido acordo ora avulta não ter sido de todo infundada.

Indubitavelmente, a ciência de suas limitações e defasagens tecnológicas - que 
no caso de alguns decorre de um histórico nacional de colonização e imperialismo, no caso de outros de uma política externa subserviente e acomodada -, os impedia de acreditar na concretização das tantas virtudes anunciadas como predicados do Acordo TRIPS.

Assim como é inquestionável que devem os Estados-membros menos desenvolvidos e em desenvolvimento envidar esforços no sentido da estruturação de um sistema nacional de inovação, é igualmente certo que, diante da progressiva tendência de internacionalização do mercado, isso só será possível mediante uma reflexão acerca das conquistas alcançadas e desafios a serem enfrentados pelo Acordo TRIPS. E quanto aos desafios, o primeiro deles é certamente dar maior efetividade aos objetivos em seu bojo declarados, que até então permanecem como letra morta.

Talvez agora, que já foi cumprido o cronograma de internalização dos padrões mínimos por parte dos Estados-membros em desenvolvimento, o que constituía a preocupação precípua do Conselho do TRIPS ao longo dos últimos anos, possam as atenções se voltar ao menos um pouco no sentido da implementação dos objetivos subjacentes ao TRIPS e possa o referido acordo atuar como colaborador da superação do paradigma periferia-centro e não como seu algoz perpetuador.

O caminho para tanto parece partir de um necessário balanceamento dos interesses atrelados à proteção da propriedade intelectual, a ser alcançado durante as Rodadas de Negociação da OMC - caso, obviamente, se suplantem as barreiras já apresentadas na atual Rodada de Doha, que tanto dificultam seu sucesso e impedem a celebração de um texto final que a conclua - mediante a provocação dos Estadosmembros em desenvolvimento que hão de adotar uma postura mais ativa e uníssona.

O passo inicial seria uma mudança de olhar sobre o Acordo TRIPS, que já não pode mais ser interpretado como um simples mecanismo de codificação da propriedade intelectual, devendo isso sim assumir o papel de um sistema internacional de inovação, operacionalizando, exemplificativamente, dispositivos em seu bojo adormecidos como o que contém o compromisso dos Estados-membros desenvolvidos de promover e incentivar a transferência de tecnologia para os Estados-membros menos desenvolvidos. Esta, todavia, é questão intrincada, que extrapola o objeto do presente estudo e demanda análise pormenorizada que indubitavelmente será obra de trabalhos ulteriores.

Por ora, vale apenas refletir que a propriedade intelectual, muito além de commodity no mercado internacional, é parte dos meios para a consecução de um fim a ser 
levado em consideração dentro de uma estratégia maior de promoção do desenvolvimento econômico e do bem estar social mundial. Seu papel pode ser de destaque dentro da estratégia da OMC para alcançar o crescimento econômico e sua existência pode ser importante por si só. No entanto, não se pode jamais perder de vista que o objetivo precípuo da OMC é melhorar os padrões mundiais de vida e não proteger a propriedade intelectual.

\section{Referência Bibliográficas}

ADEDE, A. O. The political economy of the trips a greement: origins and history of negotiations. Disponível em <http://www.ppl.nl/bibliographies/wto/files/1273.pdf>. Acesso em 21 de fevereiro de 2018.

ABBOTT, Frederick M. The enduring enigma of TRIPS: a challenge for the world economic system. Journal of International Economic Law, vol. 1, artigo 4, p. 497 -521, Oxford University Press. Disponível em <http://papers.ssrn.com/sol3/papers.cfm?abstract_id=915040>. Acesso em 15 de março de 2018.

CARLSOON, Bo. Internationalization of Innovation Systems: A Survey of the Literature. Disponível em <http://www.sussex.ac.uk/Units/spru/events/KP_Conf_03/documents/Carlsson.pdf>. Acesso em 13 de março de 2018.

CHANG, Ha-Joon. Chutando a escada. Tradução de Luiz Antônio Oliveira de Araujo. São Paulo: Ed. Unesp, 2004.

GONTIJO, Cícero. As transformações do Sistema de Patentes, da Convenção de Paris ao Acordo TRIPS. A posição brasileira. Disponível em <http://fdcl berlin.de/fileadmin/fdcl/Publ ikationen/C_cero -FDCL.pdf>. Acesso em 31 de março de 2018.

Museu Paraense Emílio Goeldi. Curso de Introdução à Propriedade Intelectual. Disponível em <http://www.nittec.i fsudestemg.edu.br/principal/doc/apostila_pi.PDF >. Acesso em 22 de janeiro de 2018.

NELSON, Richard R. As fontes do crescimento econômico. Tradução: Adriana Gomes de Freitas. São Paulo: Ed. Unicamp, 2006.

SHEKHAR, Soumya. TRIPS and developing countries. Disponível em <http://www.legalindia.in/trips -and- developing-countries>. Acesso em 20 de março de 2018. SRINIVASAN, T. N., The TRIPS Agreement: A Comment Inspired by Frederick Abbott's Presentation. Disponível em: <http://www.econ.yale.edu/ srinivas/TRIPS.pdf >. Acesso em 19 de março de 2018.

TAWFIK, Myra J. Is the WTO/TRIPS Agreement User -Friendly? Disponível em: <http://www.cla.ca/AM/Template.cfm?Section=International_Trade_Treaties_Working_Gro up\&Template=/CM/ContentDisplay.c fm\&Content $\mathrm{ID}=2553>$. Acesso em 31 de março de 
2018.

VARELLA, Marcelo Dia; ROCHA DA SILVA, Alice. A mudança de orientação da lógica de solução das controvérsias econômicas internacionais. Revista Brasileira de Política Internacional. V. 49, n. 2, Brasília, jul/dez. 2006. Disponível em: <http://www.scielo.br/scielo.php?pid=S003473292006000200002\&script=sci_arttext $>$. Acesso em 31 de janeiro de 2018.

YU, Peter K. The objectives and Principles of the TRIPS Agreement. Disponível em: <http://www.peteryu.com/correa.pdf >. Acesso em 29 de março de 2018.

WIPO Intellectual Property Handbook: Policy, Law and Use. Disponível em: <http://www.wipo.int/export/sites/www/about -ip/en/iprm/pdf/ch1.pdf >. Acesso em 22 de fevereiro de 2018. 